\title{
Preparation of Chitosan-Polyethylene Oxide-Colocasia esculenta Flour Nanofibers using Electrospinning Method
}

\author{
Riesca Ayu Kusuma Wardhani ${ }^{*}$, Lia Asri ${ }^{2}$, Muhamad Nasir ${ }^{3}$, Bambang Sunendar \\ Purwasasmita $^{1,4}$ \\ ${ }^{1}$ Advanced Materials Processing Research Group, Engineering Physics Study Program, Institut \\ Teknologi Bandung, Jl. Ganesha 10, Bandung, 40132, Indonesia \\ ${ }^{2}$ Materials Engineering Study Program, Institut Teknologi Bandung, Jl. Ganesha 10, Bandung, 40132, \\ Indonesia \\ ${ }^{3}$ Research Center for Chemistry, Indonesian Institute of Sciences, Jl. Sangkuriang Komplek LIPI, \\ Bandung, 40135, Indonesia \\ ${ }^{4}$ Research Center for Nanosciences and Nanotechnology, Institut Teknologi Bandung, Jl. Ganesha 10, \\ Bandung, 40132, Indonesia \\ *Corresponding author: riesca.wardhani@gmail.com
}

\begin{abstract}
Nanofibers have been prepared from the mixture of chitosan, polyethylene oxide (PEO) and Colocasia esculenta flour (CE flour) by using the electrospinning method. Two different nanofibers were formulated, containing chitosan-PEO and chitosan-PEO-CE flour. The higher concentration of PEO (3\%chitosan-6\%PEO) (w/v) resulted in more uniform chitosan-PEO electrospun nanofibers without beads. Chitosan-PEO-CE flour was prepared by addition of colloidal CE flour into the solution containing 3\%chitosan-6\%PEO with variation of the CE flour concentration of 5, 15 and $25 \%$ (w/v). Scanning Electron Microscopy demonstrated that the average diameter of chitosan-PEO nanofibers was $128 \pm 41 \mathrm{~nm}$, whereas the diameter of chitosan-PEO-CE flour nanofibers was $159 \pm 45 \mathrm{~nm}$. The diameters of nanofibers increased with the increase of CE flour content. Fourier transform infrared spectra demonstrate the presence characteristic peaks of chitosan, PEO and CE flour.

Copyright $\odot$ 2019. Journal of Mechanical Engineering Science and Technology

All rights reserved
\end{abstract}

Keywords: Chitosan, Colocasia esculenta, electrospinning, nanofibers, polyethylene oxide.

\section{Introduction}

The use of biopolymers such as protein (collagen and fibrin) and polysaccharides (cellulose, chitosan, and hyaluronic acid) as biomaterials for wound healing has attracted many attentions in the biomedical field. These biopolymers provide many instructive cues required by the cells attachment and proliferation [1]. Colocasia esculenta flour (CE flour) is known as botanical collagen due to its some essential amino acid contents (protein). It has been reported that $C$. esculenta can be used in medicine, skin wounds healing [2][3] and as poison antidote [4][5]. Carbohydrates and some essential amino acids contents in $C$. esculenta make this material is not toxic and compatible with the body. Wound dressing has to be antibacterial, the addition of antibacterial agent then becomes important. Chitosan is one of biopolymer that has antibacterial properties, biocompatible, and biodegradable. Chitosan is obtained from $\mathrm{N}$-deacetylation of chitin, the second-most abundant natural polysaccharide, which is embedded in a protein matrix of a crustacean shell [6]. CE flour and chitosan are good candidates to be used as a wound dressing. 
Electrospinning has been regarded as the most promising approach to generate continuous nanofibers on a large scale, and the fiber diameter can be adjusted from nanometers to micrometers. Electrospun nanofiber is a good wound dressing candidate because of its unique properties: the highly porous structure and well-interconnected pores are particularly important for exuding fluid from the wound. The small pores and very high specific surface area not only prevent the microorganism invasions but also assist the control of fluid drainage [7]-[9]. Electrospun chitosan-PEO nanofiber containing $\mathrm{CE}$ flour has not been reported. In the present study, we describe how we have adapted the electrospinning process to fabricate nanofibers of chitosan and PEO with containing CE flour. Polyethylene oxide (PEO), a stable polymer, easily soluble in water, non-toxic and non-irritating, was also added to decrease the conductivity of the polysaccharide content and to regulate the polymer chain entanglement in the solution [10]. Combination of PEO and biopolymers is expected to result in nanofibers that are easily fabricated and has excellent properties for wound dressing.

\section{Materials and Methods}

\section{A. Materials}

Chitosan with low molecular weight $(\mathrm{Mw}=20000 \mathrm{Da}$, deacetylation degree $=75$ $85 \%)$ and polyethylene oxide $(\mathrm{PEO}, \mathrm{Mw}=600000 \mathrm{Da})$ were purchased from Sigma. Acetic acid glacial was obtained from Merck. CE flour was kindly provided by PT. Sentra Biogen Bandung, Indonesia. CE flour contains protein of $12.92 \%$ consisting of 17 different amino acids, carbohydrate of $71.05 \%$, and fat of $0.91 \%$.

\section{B. Methods}

Various concentrations of polymers solutions were prepared using different solvents. PEO solutions were prepared with concentrations of $4 \%-6 \%(\mathrm{w} / \mathrm{v})$ in deionized water, while chitosan solutions were made with concentrations of $3 \%-4 \%$ $(\mathrm{w} / \mathrm{v})$ in $80 \%(\mathrm{v} / \mathrm{v})$ acetic acid. CE flour colloidal solutions were prepared with concentrations of 5, 15, and $25 \%(\mathrm{w} / \mathrm{v})$ in deionized water. Afterward, chitosan and PEO solutions were mixed with volume ratio 40:60 under stirring for 24 hours at room temperature. Chitosan-PEO-CE flour solution was prepared by adding $1 \mathrm{~mL} \mathrm{CE}$ flour colloidal solution into $20 \mathrm{~mL}$ solution containing $3 \%$ chitosan $-6 \%$ PEO with a volume ratio of chitosan: PEO of 40:60. The mixture was stirred for 24 hours at room temperature until the solution was homogeneous. The chitosan-PEO and chitosan-PEO$\mathrm{CE}$ flour solutions were processed by electrospinning (built-up electrospinning apparatus VF-S11, Research Center for Chemistry, Indonesian Institute of Sciences, Indonesia). Electrospuns were collected on a plate drum by connecting a high voltage power supply. A syringe pump was used for delivering the polymer solution at a rate from $0.005 \mathrm{~mL} / \mathrm{min}$ with a voltage from 15 to $20 \mathrm{kV}$ and a needle to collector distance of $12 \mathrm{~cm}$.

\section{Characterizations}

The morphologies of the nanofibers were examined using a Scanning Electron Microscope (SEM) JEOL-JSM-6360LA. The nanofibers samples were sputter-coated with gold. The average diameter of nanofibers was determined by selecting 100 fibers 
at random from SEM images with 1000x magnification. FTIR spectra of nanofibers were measured using Attenuated Total Reflectance Fourier Transform Infrared (ATR-FTIR) spectroscopy, recorded on Bruker Alpha FTIR Spectrometer with a wave number of $4000-750 \mathrm{~cm}^{-1}$.

\section{Results and Discussions}

Figure 1 shows SEM images of chitosan-PEO electrospuns, confirming that nanofibers structure have been successfully formed in all solution compositions. The best condition used in electrospinning parameters was obtained at a voltage of $20 \mathrm{kV}$, polymer solution flow rate of $0.005 \mathrm{~mL} / \mathrm{min}$, and the distance between the nozzle collector of $12 \mathrm{~cm}$.
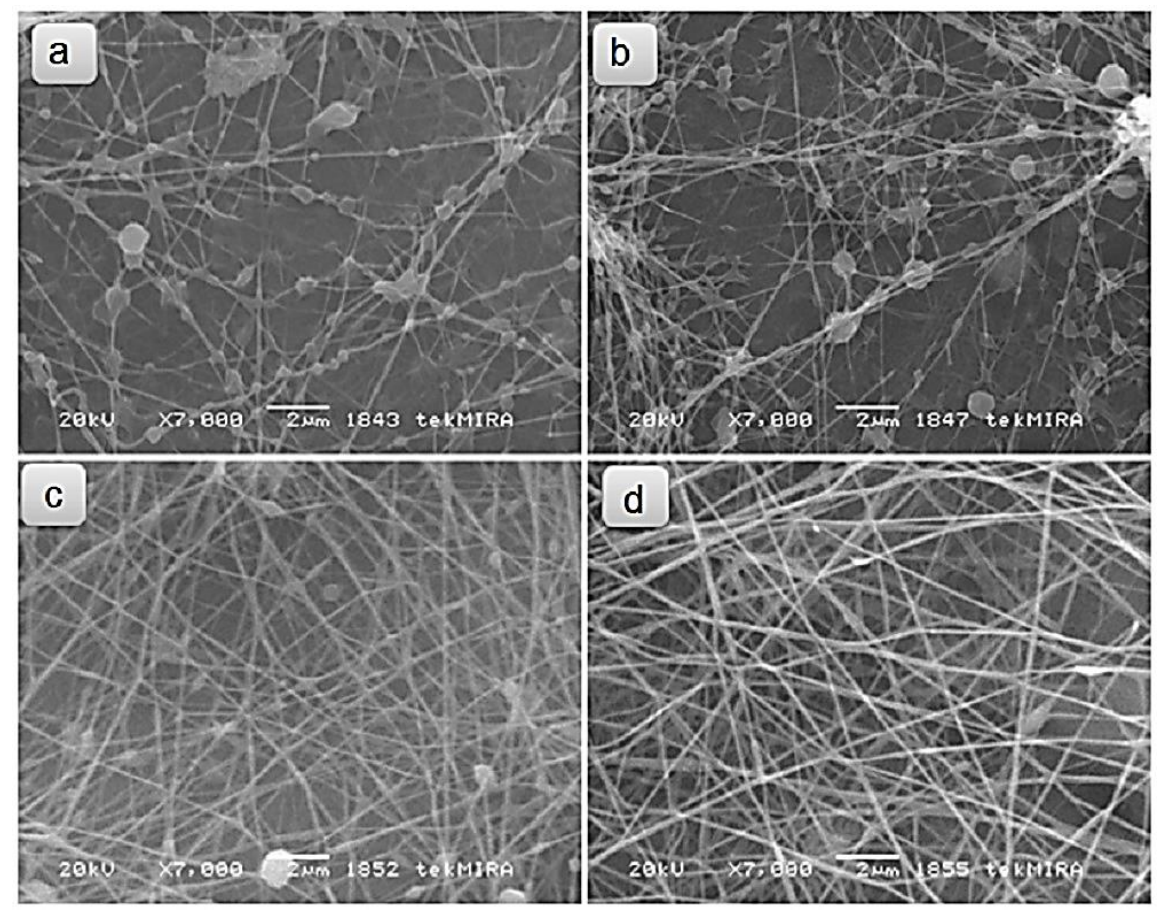

Fig. 1. SEM morphologies of Chitosan-PEO electrospuns nanofibers were collected from solutions containing (a) 3\% chitosan - 5\% PEO; (b) 4\% chitosan - 4\% PEO; (c) 4\% chitosan-5\% PEO; (d) $3 \%$ chitosan $-6 \%$ PEO. The bar denotes $2 \mu \mathrm{m}$.

The diameter of the fibers chitosan-PEO ranged from 41 to $262 \mathrm{~nm}$, with the average fiber diameter of $128 \pm 41 \mathrm{~nm}$. It is found that some of nanofibers still contain beads (Figure 1a-c), showing that the concentration of polymer solutions was not high enough to tie chitosan and PEO chains. Nanofibers from 4\% chitosan - 5\% PEO (Figure 1c) showed fewer beads than 3\% chitosan $-5 \%$ PEO (Figure 1a) and $4 \%$ chitosan $-4 \%$ PEO (Figure 1b), whereas beads were not observed in nanofibers obtained from 3\% chitosan $-6 \%$ PEO solution (Figure 1d). From the SEM images, it can be concluded that the best concentration of the solution used in electrospinning was found at $3 \%$ chitosan and 6\% PEO. The higher concentration of PEO $(6 \%)$ resulted in more uniform electrospun nanofibers as the long PEO molecular chains can make other molecular 
chains fully stretch and effectively entangle with each other in solution [11][12]. A number of PEO molecules at this concentration was sufficient to balance the amount of molecular chains of chitosan, so that interlacing fibers were able to form the uniform nanofibers without beads. The 3\% chitosan and 6\% PEO concentration was then used in the formation of chitosan-PEO-CE flour nanofibers.

The best condition used in electrospinning process of chitosan-PEO-CE flour solution was set at a voltage of $15 \mathrm{kV}$, polymer solution flow rate of $0.005 \mathrm{ml} / \mathrm{min}$., and the distance between the nozzle - collector of $12 \mathrm{~cm}$. Formation of chitosan-PEO-CE flour nanofibers required lower voltage than chitosan-PEO nanofibers $(20 \mathrm{kV})$. Addition of CE flour into chitosan solution could strongly increase the conductivity of the solution that makes the solution is difficult to be processed by electrospinning. Chen et al. reported the influence of polymer on solution conductivity following this order: collagen (protein) > chitosan > PEO [13]. The CE flour consists of carbohydrate as major component, protein (17 amino acids), and fat. Protein (12.92\%) contents seem responsible in increasing the solution conductivity. The presence of PEO in the solution plays a role not only in promoting chain entanglement of polymers but also decreasing the conductivity of polymer solution [10].
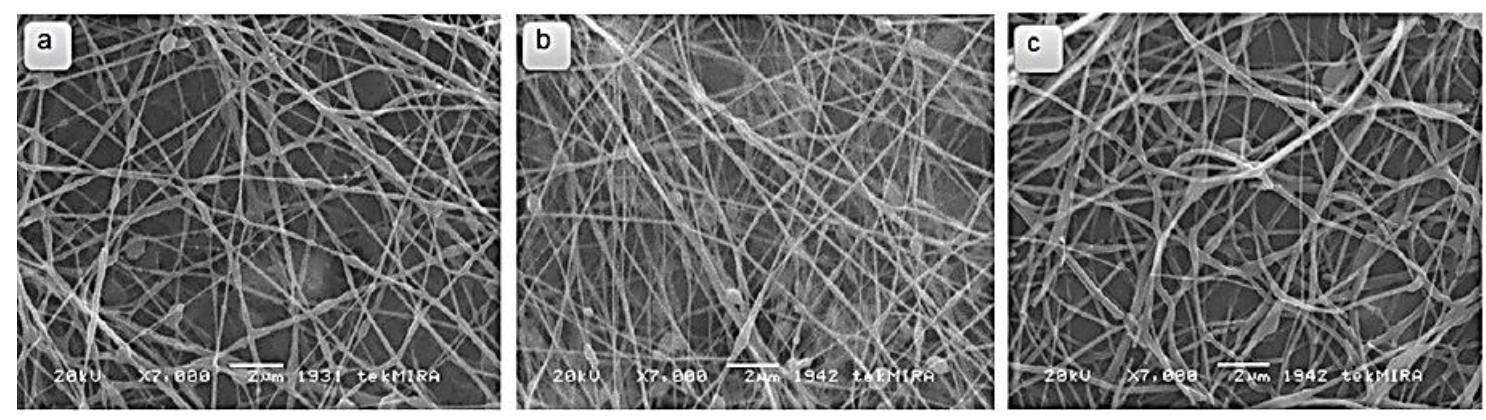

Fig. 2. SEM morphologies of chitosan-PEO-CE flour nanofibers. Electrospuns were collected from solutions of $3 \%$ chitosan $-6 \% \mathrm{PEO}$ and various concentrations of $\mathrm{CE}$ flour (a) $5 \% \mathrm{CE}$ flour; (b) $15 \%$ CE flour; (c) $25 \%$ CE flour. The bar denotes $2 \mu \mathrm{m}$.

SEM images confirm the formation of nanofibers for all concentration of CE flour (Figure 2). The smooth nanofibers were observed at a concentration of $25 \% \mathrm{CE}$ flour (Figure 2c), whereas a small number of beads were still found in nanofibers with CE flour content of 5 and $15 \%$ (Figure 2a-b). It can be concluded that solution containing $3 \%$ chitosan $-6 \%$ PEO - 25\% CE flour was the best composition among other formulations. The diameter size of resulting chitosan-PEO-CE flour nanofibers range from 50 to $292 \mathrm{~nm}$ with an average fiber diameter of $159 \pm 45 \mathrm{~nm}$, indicating slightly bigger than the diameter of chitosan-PEO nanofibers. In this works, the electrospinning parameters indicated that the increase of higher power supply voltage caused a faster rate as the process of spinning mass rate of the polymer out of the nozzle also increased so that the diameter of the fibers were smaller [9]. Nanofiber diameters increased with the increase of CE flour content as solution became more conductive. When the solution subjected to an electric field, the fiber jet was easier to be withdrawn. Higher voltages were applied during electrospinning (16-18 kV) in order to decrease the diameter of the fiber, but it resulted in discontinuous structure of nanofibers. 
To confirm the chemical composition of the electrospun nanofiber, ATR-FTIR was employed. Afterward, the FT-IR spectrum of chitosan-PEO-CE flour nanofiber was compared to the electrospun chitosan-PEO, and electrospun PEO nanofibers (Figure 3).

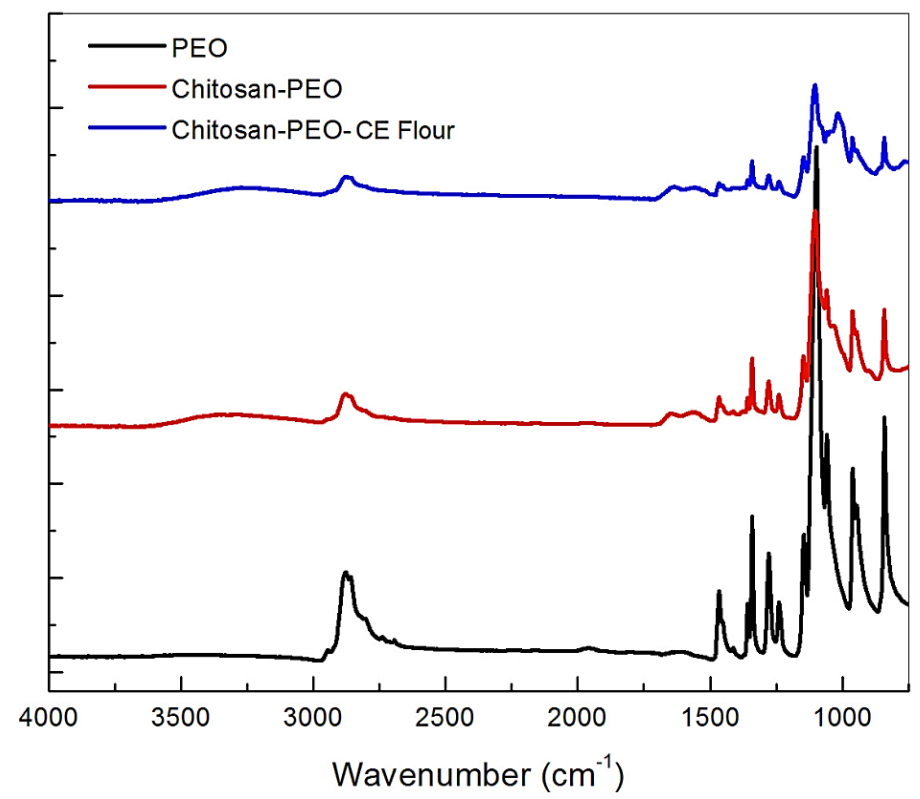

Fig. 3. ATR-FTIR spectra of PEO, chitosan-PEO, and chitosan-PEO-CE flour nanofibers.

Electrospun PEO displays absorption peaks at $2885 \mathrm{~cm}^{-1}$ originating from $-\mathrm{CH}_{2}-$ stretching vibrations, $1465 \mathrm{~cm}^{-1}$, at $1363 \mathrm{~cm}^{-1}, 1340 \mathrm{~cm}^{-1}, 1279 \mathrm{~cm}^{-1}, 1241 \mathrm{~cm}^{-1}$, and 845 $\mathrm{cm}^{-1}$ indicates the presence of $\mathrm{CH}$ bending, peaks of the C-O-C stretching vibrations at $1149 \mathrm{~cm}^{-1}, 1101 \mathrm{~cm}^{-1}, 1062 \mathrm{~cm}^{-1}$ and $959 \mathrm{~cm}^{-1}$ [12]. The characteristic absorption peaks of chitosan appear in the area of $3600 \mathrm{~cm}^{-1}-3000 \mathrm{~cm}^{-1}$ indicating the presence of O-H and $\mathrm{N}-\mathrm{H}$ stretch, peak at $1655 \mathrm{~cm}^{-1}$ originating from $-\mathrm{C}=\mathrm{O}$ stretch and at $1570 \mathrm{~cm}^{-1}$ from the amide bond $-\mathrm{NH}_{2}$. The two absorption peaks $-\mathrm{CH}_{2}-$ at $2885 \mathrm{~cm}^{-1}$ and $\mathrm{C}-\mathrm{O}-\mathrm{C}$ at 1101 $\mathrm{cm}^{-1}$ were observed for PEO. For electrospun chitosan-PEO-CE flour, each absorption peaks of chitosan and PEO are identified, while the typical absorption bands of chitosan and PEO represent $-\mathrm{CH}_{2}-$ stretching and $-\mathrm{NH}_{2}$ did not change. The absorption peaks of amide I $\left(1650 \mathrm{~cm}^{-1}\right)$ and amide II $\left(1550 \mathrm{~cm}^{-1}\right)$ indicate characteristic of structure protein and chitosan.

\section{Conclusions}

Nanofibers have been successfully prepared from solutions containing chitosanPEO and chitosan-PEO-CE flour using the electrospinning method. SEM analysis of the resulting electrospuns confirms the formation of nanofibers. It shows that the optimum concentration on nanofibers formation with braided fibers are uniform without any beads in concentrations of $3 \%$ chitosan, $6 \%$ PEO, and 25\% CE flour. FTIR analysis shows the existence of CE flour, chitosan, and PEO on the surface of the nanofiber membrane as indicated by some characteristic peaks in FTIR spectra. 


\section{Acknowledgment}

This work was supported by Lembaga Pengelola Dana Pendidikan (LPDP), Ministry of Finance Republic Indonesia.

\section{References}

[1] Agarwal, S., Wendorff, J.H., and Greiner, A, "Use of electrospinning technique for biomedical applications", Polymers, vol. 49, pp. 5603-5621, 2008.

[2] Agyare, C., Asase, A., Lechtenberg, M., Niehues, M., Deters, A., and Hensel, A, "An ethnopharmacological survey and in vitro confirmation of ethnopharmacological use of medicinal plants used for wound healing in bosomtwi-atwima-kwanwoma area, Ghana", Journal of Ethnopharmacology, vol. 125, pp. 393-403, 2009.

[3] Goncalves, R.F., Silva, A.M.S., Silva, A.M., Valentao, P., Ferreres, F., Izquierdo, A.G., Silva, J.B., Santos, D., and Andrade, P.B, "Influence of taro (Colocasia esculenta L. Shott) growth conditions on the phenolic composition and biological properties", Food Chemistry, vol. 141, pp. 3480-3485, 2013.

[4] Nwauzom,a A.B., and Dappa, M.S, "Ethnobotanical studies of port harcourt metropolis, Nigeria", ISRN Botany, Article ID 829424, 2013.

[5] Prajapati, R., Kalariya, M., Umbarkar, R., Parmar, S., and Sheth, N, "Colocasia esculenta: A potent indigenous plant", International Journal of Nutrition, Pharmacology, Neurological Diseases, vol. 1, no. 2, pp. 90-96, 2011.

[6] Geng, X., Kwon, O.H., and Jang, J, "Electrospinning of chitosan dissolved in concentrated acetic acid solution", Biomaterials, vol. 26, pp. 5427-5432, 2005.

[7] Zahedi, P., Rezaeian, I., Siadat, S., Jafari, S.H., and Supaphol, P, “A review on wound dressings with an emphasis on electrospun nanofibrous polymeric bandages", Wiley InterSciences, vol. 21, pp. 77-95, 2010.

[8] Huang, Z.M., Zhang, Y.Z., Kotaki, M., and Ramakrishna. S., "A Review on Polymer Nanofibers by Electrospinning and Their Applications in Nanocomposites", Composite Science and Technol., vol. 63, pp. 2223-2253, 2003.

[9] Sill, T.J., and Von. R.H.A, "Electrospinning: Application in drug delivery and tissue engineering", Biomaterials, vol. 29, pp. 1989-2006, 2008.

[10] Jeong, S.I, Krebs., Melissa, D., Khan, S.A., Bonino., Christopher, A., Samorezov., Julia, E., and Alsberg, "Electrospun chitosan-alginate nanofibers with in situ polyelectrolyte complexation for use as tissue engineering scaffolds", Tissue Engineering. Part A, vol. 17, no. 1-2, pp. 59-70, 2011.

[11] Sun, K., and Li, Z.H, "Preparations, properties and applications of chitosan based nanofibers fabricated by electrospinning", Express polymer letters, vol. 5, pp. 342-361, 2010.

[12] Chen, L., Zhu, C., Fan, D., Liu, B., Ma, X., Duan, Z., and Zhou, Y, “A human-like collagen/chitosan electrospun nanofibrous scaffold from aqueous solution: 
electrospun mechanism and biocompatibility", Biomedical Material, vol. 99A, pp. 395-409, 2011.

[13] Chen, J.P., Chang, G.Y., and Chen, J.K, "Electrospun collagen/chitosan nanofibrous membrane as wound dressing", Colloids and Surfaces, vol. 313, pp. 183-188, 2008. 